\begin{tabular}{|c|c|}
\hline $\begin{array}{c}\text { ÇÜTAD } \\
\text { Cukurova Üniversitesi } \\
\text { Türkoloji Araștırmaları Dergisi }\end{array}$ & $\begin{array}{c}\text { Cilt 5, Sayı } 1 \\
\text { Haziran } 2020\end{array}$ \\
\hline $\begin{array}{c}\text { ISSN: } 2587-1900 \\
\text { E-ISSN: } 2548-0979\end{array}$ & : 17.04 .2020 \\
\hline $\begin{array}{l}\text { Makale Künyesi (Tanıtma): Y1lm } \\
\text { Osmanlıca. [Osmanlıca adlı kitap } \\
\text { Türkoloji Araştırmaları Dergisi. } 5 \text { (1), }\end{array}$ & $\begin{array}{l}\text { Haluk Gökalp / } \\
\text { ova Üniversitesi }\end{array}$ \\
\hline
\end{tabular}

\title{
HALUK GÖKALP/ OSMANLICA
}

Elif YILMAZ ${ }^{1}$

Türk Edebiyatının tarihî gelişiminde, Arapça ve Farsçanın kuvvetli tesiri ile yaklaşık altı yüzyıl devam eden ve "Osmanlıca / Osmanlı Türkçesi" şeklinde isimlendirilen bir medeniyet dili oluşmuştur. Namık Kemal'in meşhur deyişiyle "Küçük bir aşiretten çıkmış cihangirâne bir devlet olan Osmanlı"nın dili -Osmanlıca- ile ilgili bugüne kadar pek çok bilimsel çalışma yapılmış ve yapılmaya devam etmektedir. Bildiri, makale ya da kitap olarak hazırlanan çalışmalarda Osmanlı Türkçesinin öğretilmesinde temel olan ve öğrenilmesinde zorluk yaşanılan konular ele alınmış ve Osmanlıca sahasının gelişimine katkıda bulunmak amaçlanmıştır.

Osmanlıca sahasında var olan değerli çalışmaların yanı sıra son dönemlerdeki çalışmalardan biri de Çukurova Üniversitesi Türk Dili ve Edebiyatı alanında çalışmalarını devam ettiren Prof. Dr. Haluk Gökalp’in 2018 yılında yayımladığı "Osmanlıca" adlı kitabıdır. Yazar, çalışmasının “Ön Söz”ünde, Osmanlıca alanında geçmişte hazırlanan birbirinden değerli çalışmaların varlığından bahsetmekle birlikte Türk Dili ve Edebiyatı bölümü müfredatına tam anlamıyla uyan bir kitaba ihtiyaç duyulduğuna da dikkat çekmektedir. Araştırmacı, çalışmasının Osmanlıca ile ilgili eksikliklerin giderilmesi için kaleme alındığını şu sözlerle ifade etmiştir.

Gerek öğrenci gerekse öğretim üyesi sıfatıyla yirmi yıldır öğrenmeye ve öğretmeye gayret ettiğim Osmanlıcanın her yıl yeni bir yönünü keşfetmenin mutluluğunu yaşıyorum. Sevgili öğrencilerimin ve yayınevimin isteği üzerine yıllardır Çukurova Üniversitesi Türk Dili ve Edebiyatı ve Türkçe bölümlerinde yürüttüğüm Osmanlıca derslerim sırasında kazandığım tecrübe 1şı̆̆ında öğrencilerimizin ihtiyaçlarını dikkate alarak bir Osmanlıca kitabı yazmaya karar verdim. Birbirinden değerli Osmanlıca kitapları bulunmasına rağmen Osmanlıca kitabı yazma kararımda birinci etken Türk Dili ve Edebiyat bölümü "müfredatımıza" tam anlamıyla uyan bir kitaba duyulan ihtiyaçtır (Gökalp, 2018, s. xiv).

\footnotetext{
${ }^{1}$ Çukurova Üniversitesi, Sosyal Bilimler Enstitüsü, Türk Dili ve Edebiyatı Ana Bilim Dalı, Yüksek Lisans Öğrencisi. elf.elf.47@hotmail.com https://orcid.org/0000-0003-2429-6072
} 
Araştırmacının "Osmanlıca" adlı kitabının ilk baskısı Şubat 2018'de yapılmıştır. Çalışma, Karahan Kitabevi Yayınları'ndan çıkan ve 780 sayfadan oluşan oldukça hacimli bir kaynaktır. Eser, çalışmanın yöntemine dair bilgilerin sunulduğu ön söz, yirmi altı ana bölüm, kendisini geliştirmek isteyen öğrenciler için on beş "Ek" bölüm, yirmi okunmuş metin, otuz sekiz metin, on sekiz basma ve yazma metinler bölümü ile kaynakçadan oluşmaktadır.

Kitabın bölümleri ve bölümlerin içerikleri aşağıda verilmiştir:

Eserin ilk iki bölümünü, “Alfabe” (Gökalp, 2018, s. 1-4) ve "Harflerin Bitişmesi” (Gökalp, 2018, s. 5-16) üniteleri oluşturmuştur. $\mathrm{Bu}$ ünitelerde yazar, Osmanlı Türkçesinin yazımında kullanılan alfabeyi ve Farsların dillerindeki bazı seslerin ifade edilmesi için yeni seslerin eklendiğini anlatıp benzer seslerin ayırt edilmesi için tablo hazırlamıştır. Harflerin bitiştirilmesinde bazı değişikliklerin ortaya çıktığına değinmiştir.

Üç ve dördüncü bölümde, "Türkçe ve Alıntı Sözcüklerin Yazımı" (Gökalp, 2018, s. 17-22) ile "Alıntı Sözcükleri Türkçe Sözcüklerden Ayırt Etme" (Gökalp, 2018, s. 23-26) başlıkları işlenmiştir. Türkçe sözcükleri alıntı sözcüklerden ayırt etme hususunda kurallar bu bölümlerde verilmiştir. Türkçe sözcüklerle birlikte Arapça ve Farsça sözcüklere sıklıkla yer verilmiştir. Her üç dilden de sözcüklerin bulunmasından dolayı harflerin Türkçe sözcüklerin yazımında farklı, alıntı sözcüklerin yazımında farklı kullanıldığına dikkat çekilmiştir.

Türkçe ünlü harfler yönü ile zengin bir dildir. Arapça ise ünsüz harfler yönü ile zengindir. Türkçede uzun ünlü bulunmaz iken Arapça ve Farsçada kısa ünlülerin yanı sıra uzun ünlüler de mevcuttur. Türkçedeki ünlü harflerin yazımı kalıplaşmamıştır. Arapçada ise dört harf birden fazla ünlüyü karşılamaktadır. Bu sebeplerden dolayı Türkçe ve alıntı sözcüklerin yazımında farklı kurallar uygulanmaktadır. Yazar, Türkçe ve alıntı sözcüklerdeki farklılıkları açıklamak için beşinci ve altıncı bölümü "Türkçe Sözcüklerde Ünlülerin Yazımı” (Gökalp, 2018, s. 27-34) ile “Türkçe Sözcüklerde Kalınlık -İncelik Ayrımı” (Gökalp, 2018, s. 35-40) konularına ayırmıştır.

Yedi ve sekizinci bölümü oluşturan "Alıntı Sözcüklerde Ünlüler" (Gökalp, 2018, s. 41-46) ile "Yardımcı İşaretler" (Gökalp, 2018, s. 47-52) örneklerle açıklanmıştır. "Yardımcı İşaretler" bölümü, üstün (fetha), esre (kesre), ötre (damme), cezm, tenvin ve şedde alt başlıklarına ayrılarak ele alınmıştır. Şedde konusunda diğer kaynak kitaplarda belli başlı örnekler tekrar edilmiştir. Gökalp ise şedde ile ilgili örneklerin tamamına yer vermiştir. 
Nazal n (Genizsi n) Türkçeye özgü bir sestir. Nazal n (Genizsi n), harfinin Arap alfabesinde "kef" harfi ile de yazılabilmesi okuma esnasında öğrenenlere zorluk çıkarmaktadır. Bu durumda yaşanan karışıklığın nasıl giderileceğini anlatmak için yazar dokuzuncu bölümde "Nazal n (Genizsi n)” (Gökalp, 2018, s. 53-56) başlığına yer vermiştir. Onuncu ünite “Türkçe Ekler” (Gökalp, 2018, s. 57-66) konusuna ayrılmıştır.

Arapçaya özgü olan ayın ve hemze konuları on bir ve on ikinci bölümde "Ayın Harfli Sözcükler" (Gökalp, 2018, s. 67-76) ile "Hemze” (Gökalp, 2018, s. 77-82) başlıkları altında ayrıntılı olarak işlenmiştir. Arapçaya özgü olan bu iki harfin sözcük başında, sözcük içinde ve sözcük sonundaki şekilleri verilerek örneklerle zenginleştirilmiştir. Ayın ve hemze ile ilgili örnekler mevcut Osmanlıca kaynaklardaki örnekler ile sınırlandırılmamıştır. Yazar, konu ile ilgili örneklerin tamamına yer vermiştir.

On üçüncü bölümde “İmlada Özel Durumlar” konusuna değinilmektedir (Gökalp, 2018, s. 83-88). Konu kapsamında "Vav-1 Ma'dûle" ve "Elif-i Maksûre” ye ayrıntılı şekilde yer verilmiştir. "Vav-1 Ma'dûle" konusundan itibaren araştırmacı alıntı sözcükleri sözlük anlamları ile birlikte vermiştir. Kullanılan örneklerin sözlük anlamları sayesinde öğrenenlerin sözcük dağarcığının geliştirilmesi yazar tarafından hedeflenmiştir.

Son on üç bölümde sırası ile "Sayılar, Günler, Aylar" (Gökalp, 2018, s. 89-94), "Arapça ve Farsça Tamlamalara Giriş" (Gökalp, 2018, s. 95-104), “Farsça Sözcüklerde Çokluk” (Gökalp, 2018, s. 105110), “Arapça Sözcüklerde Çokluk” (Gökalp, 2018, s. 111-122), "Halklılaştırma” (Gökalp, 2018, s. 123-132), "Farsça Fiiller” (Gökalp, 2018, s. 133-146), "Farsça Fiilden Türemiş İsimler ve Sıfatlar" (Gökalp, 2018, s. 147-156), "Farsça Birleşik Sözcükler" (Gökalp, 2018, s. 157-174), “Atıf Terkipleri” (Gökalp, 2018, s. 175- 182), "İsimden Türemiş İsimler ve Sıfatlar" (Gökalp, 2018, s. 183-216), "Farsça Edatlar ve Zarflar" (Gökalp, 2018, s. 217-224), "Farsça İsim Tamlamaları" (Gökalp, 2018, s. 225-242) konuları ele alınmıştır. Arapça ve Farsça tamlama çeşitlerinin tamamından söz edilerek örneklendirilmiştir.

Halklılaştırma sorunu Arapça ve Farsça sözcüklerdeki yabancı seslerin Türkçeye uyarlanması sonucunda karşımıza çıımıştır. Halklılaştırma ile Arapça ve Farsça sözcüklerin orijinal imlasına bağlı kalınmaya çalışılmışsa da Türkçenin etkisi ile değişimler yaşanmıştır. Halklılaştırma ünitesini alt başlıklara ayıran yazar, konuya açıklık getirmiştir. Konu ile ilgili örneklerin fazlalılığından dolayı EK-6 
bölümünü "Halklılaştırılmış Sözcüklerin Lügatçesi” ne (Gökalp, 2018, s. 297-310) ayırmıştır.

Eser, “Okunmuş Metinler” (Gökalp, 2018, s. 419-530), "Metinler” (Gökalp, 2018, s. 531-756), "Basma ve Yazma Metinler” (Gökalp, 2018, s. 757- 776) ve "Kaynakça” (Gökalp, 2018, s. 777) bölümleriyle tamamlanmıştır.

Çalışmanın örneklemini oluşturan metinler Türk ve Dünya Edebiyatı'nın farklı dönemlerinden seçilmiştir. Eserde yer alan "Okunmuş Metinler" (Gökalp, 2018, s. 419-530) kısmında çoğunlukla şiir örnekleri verilmiştir. Metinler (Gökalp, 2018, s. 531-756) bölümünde ise Batı Edebiyatı'nın yanı sıra Türk Edebiyatı'nın çeşitli dönemlerinden (Tanzimat, Servet-i Fünûn...) seçme örnekler bulunmaktadır. Çalışmada yer alan metinler, edebiyatımızın önem arz eden eserleri olması bakımından değerlidir. Bundan dolayı araştırmacılar diğer kaynaklarda gördüklerinin dışında farklı örneklerle de karşılaşmaktadır. Son olarak "Basma ve Yazma Metinler” (Gökalp, 2018, s. 757- 776) kısmında ise yazar, genellikle dîvân ve mesnevileri kullanmıştır.

Prof. Dr. Haluk Gökalp, "Osmanlıca” adlı çalışmasında yirmi tane okunmuş metin, otuz sekiz tane metin ve on sekiz tane basma ve yazma metin olmak üzere toplam yetmiş altı metine yer vermiştir. Metinler içerisinde \%50 oranı ile en fazla okunmamış metin yer almaktadır. Yazar, okunmamış metinler ile öğrencilerin transkripsiyonlu okuma yapmalarına katkıda bulunmuştur.

Gökalp'in "Osmanlıca” kitabını incelerken Osmanlıca sahasında önem arz eden çalışmalardan bazıları kullanılmış ve bu çalışmalar ile "Osmanlıca" adlı eserin arasındaki farklılıklar belirlenmeye çalışılmıştır. "Osmanlıca" adlı eser ile karşılaştırılan çalışmalar şunlardır:

Osmanlı Türkçesi Okuma Kitabı (7. bas.).

Osmanlı Türkçesi Kılavuzu (12. bas.).

Osmanlica Dersleri (46. bas.).

Osmanlı Türkçesi Metinleri II (17. bas.).

Osmanlı Büyük El Sözlüğü Türkçesi (1. bas.).

Sonuç olarak Prof. Dr. Haluk Gökalp'in "Osmanlıca" kitabı, Osmanlıca ile ilgili incelediğimiz kaynaklardan şu yönleri ile ayrilmaktadır:

- CCalışmada konu bütünlüğü yazar tarafından gözetilerek kitabın ilk yarısı birinci yarıyıl için diğer yarısı ise ikinci yarıyıl için hazırlanmıştır. Böylelikle eserin ilk yarısı ile Osmanlıcadaki temel 
unsurlar işlenmiştir. Diğer yarısında ise Farsça ve Arapça unsurlar gerekli olduğu kadar ele alınmıştır.

- Yazar, ilk üniteden itibaren konuların öğrenimi için araştırmacıların nasıl yol izlemesi gerektiğini anlatmıştır. Böylece örgün eğitimde olmayan araştırmacıların da öğrenmesini kolaylaştırmıştır.

- Kitapta anlatılan konuların pekiştirilebilmesi için her ünite sonunda "Uygulama" başlı̆ğ altında ödevler verilmiştir. Uygulama ödevlerini yapan öğrencilerin gelişimi dersi veren öğretim üyesi tarafından takip edilebilmekte ve öğretim üyelerinin işlerini kolaylaştırıcı niteliktedir.

- $\quad$ Osmanlıca, yıllar boyunca Arapça ve Farsçanın güçlü tesiri altında kalmıştır. Osmanlıca, Arapça ve Farsçanın etkisi ile geniş söz dağarcığına ulaşmış ve bu nedenle Osmanlıca öğreniminde sözlük bilgisi önem kazanmıştır. Yazar da bu gaye ile on üçüncü üniteden itibaren konu ile ilgili tüm örnek kelimelerin sözlük anlamlarına yer vermiş ve öğrencilerin söz dağarcığına katkıda bulunmuştur.

- $\quad$ Ünitelerde yer alan örnek kelimeler kendi içerisinde tablolar hâlinde verilmiş ve bu sayede yazar alışılagelmiş anlatımların dışına çıkmıştır.

- Konuların pekiştirilmesi için kullanılan kelimeler ilgili konu başlığı altında alfabetik olarak sıralanmıştır. Eser, bu özelliği ile sözlük mahiyetindedir.

- Osmanlicanın temel konularından biri olan "Halklılaştırma" sorunu diğer kaynaklarda yeterince ele alınmayarak ihmal edilen bir konu olmuştur. Yazar, "Halklılaştırma" ünitesi ile amacına yönelik önemli tespitlerde bulunmuştur. Araştırmacı "Halklılaştırılmış Sözcüklerin Lügatçesi" bölümünde ise Arapça, Farsça ve Batı kökenli sözcüklerin yer aldığı bir liste ile konunun kapsamını genişletmiştir.

- Eski Türk Edebiyatı sahasında çalışan ve kendini geliştirmek isteyen öğrenciler için on beş "Ek" bölümü yazılmıştır. "Ek" bölümlerindeki lügatçelerde Osmanlıca metinlerde karşımıza çıkma ihtimali yüksek olan çok sayıda sözcüğe anlamları ile yer verilmiştir. "Klasik Türk Şiirinde Sık Kullanılan Sözcükler” adlı ek bölümü yazan araştırmac1, bu bölüm ile öğrenicilerin sözcük dağarcığını geliştirip Eski Türk Edebiyatı sahasına da hazırlık yapmalarını sağlamıştır. 
- İncelediğimiz Osmanlıca kitaplarında "Nazal n (Genizsi n)" ve "Ayın" ile ilgili belli başlı ve tekrar eden örnekler bulunmaktadır. Ancak Prof. Dr. Haluk Gökalp "Osmanlıca" adlı eserinde Nazal n (Genizsi n) ile ilgili tarama sözlügünde yer alan bütün örneklere yer vermiştir. Ayın konusu için de Osmanlıca metinlerde karşılaşılması muhtemel örnek kelimelerin tamamı yazar tarafından kullanılmıştır.

- $\quad$ Eserde toplam yetmiş altı örnek metne yer verilmiştir. İlk olarak okunmuş metinlere yer veren yazar, öğrenicilerin öz denetim yapmasını sağlamaya çalışmıştır.

- $\quad$ Okuma metinleri farklı yazar ve şairlerin eserleri ile çeşitlendirilmiş olup metinler kolaydan zora doğru bir sıra gözetilerek verilmiştir. Metinlerin kolaydan zora doğru sıra gözetilerek verilmesi araştırmacının eserinde titiz davrandığını ve öğrenenlere kolaylık sağlamak adına hiçbir ayrıntıyı ihmal etmediğinin göstergesidir.

- Konu anlatımında yer alan eski harfli örneklerin imlasında farklı yazı stilleri kullanılmıştır. Farklı yazı stilleri ile araştırmacıların el yazması eserlere alışmasına katkıda bulunulmuştur.

- Metinlerin eski harfli biçimleri fotoğraflama yöntemi ile değil bizzat el yordamı ile yazar tarafından yazıya geçirilmiştir.

Osmanlıca öğreniminin dilbilgisi kapsamında açıklanmaya çalışıldığı bu eserin, Osmanlıca öğrenmek ve öğretmek isteyen araştırmacıların başvurabileceği kaynak kitap olması hedeflenmiştir. Yazarın çalışması ile Türk Dili ve Edebiyatı bölümü müfredatına tam anlamıyla uygun bir kitaba duyulan ihtiyaç karşılanmıştır. Çalışma, ders kitabı mahiyetinde olmakla birlikte Eski Türk Edebiyatı ana bilim dalında çalışan öğrencilere de katkı sağlayacak değerli bir eserdir. Eser, Osmanlıca ögretiminde izlenen yöntemler bakımından yapılacak çalışmalara yol gösterici niteliktedir.

\section{KAYNAKÇA}

Aksoyak, İ. H. (2011). Osmanlı Türkçesi okuma kitabı (7. bs.). Ankara: Grafiker Yayınları.

Develi, H. (2012). Osmanlı Türkçesi kılavuzu (12. bs.). İstanbul: Kesit Yayınları.

Ergin, M. (2004). Osmanlıca dersleri (46. bs.). İstanbul: Boğaziçi Yayınları.

Gökalp, H. (2018). Osmanlıca (1. bs.). Adana: Karahan Kitabevi. 
Timurtaş, F. (2015). Osmanlı Türkçesi metinleri II (17. bs.). İstanbul: Alfa Basım Yayın.

Tulum, M. (2013). Osmanlı büyük el sözlüğ̈̈ Türkçesi (1. bs.). İstanbul: Kapı Yayınları. 